\title{
PERFORMANCE ANALYSIS OF DIESEL ENGINE WITH WASTE COOKING OIL AND SC5D ADDITIVE
}

\section{P. VINDHYA ${ }^{1}$,P. ARAVINDA KEERTHI ${ }^{2}$, P. SNEHALATHA ${ }^{3} \&$ K. MOHAN ${ }^{4}$}

${ }^{1,2,4}$ Assistant Professor, Department of Mechanical Engineering, School of Engineering \& Technology, SPMVV, Tirupati, India ${ }^{3}$ Associate Professor, Department of Mechanical Engineering, School of Engineering \& Technology, SPMVV, Tirupati, India

\begin{tabular}{|l|}
\hline ABSTRACT \\
Due to rapid diminution of petroleum fuel, researchers are looking throughout the world for alternate fuels to run the \\
engines. Present days Biodiesel is a best solution to substitute for diesel fuel. Biodiesel is a completely natural, renewable \\
fuel made from biological sources like vegetable oils and animal fatty oils. In most situations, where conventional \\
petroleum such as liquefied petroleum gas, petrol, diesel, kerosene are used. In this paper, Esterified waste cooking oil is \\
blended with diesel in different proportions (B10, B20, B30\& B40). Among these proportions SC5D fuel additive is added \\
to B20 which increases performance parameters like brake thermal efficiency, indicated thermal efficiency, mechanical \\
efficiency, brake mean effective pressure, indicated mean effective pressure and decreases the brake specific fuel \\
consumption. \\
KEYWORDS: Diesel, Esterified Waste Cooking Oil \& SC5D Fuel Additive
\end{tabular}

Received: May 25, 2020; Accepted: Jun 15, 2020; Published: Jun 29, 2020; Paper Id.: IJMPERDJUN2020124

\section{INTRODUCTION}

\subsection{Vegetable Oil}

The use of vegetable oil in diesel engine is not a new concept. In fact early engines were demonstrated with vegetable oils and it has few properties namelyCetane number $(\mathrm{CN})$ and Calorific Value $(\mathrm{CV})$ similar to diesel and heat contents about $80-90 \%$ of diesel fuel. It's one of the best promising alternate to diesel, since they are renewable and easily existingin rural areas.

\subsection{SC-5DAdditive}

SC-5D is one type of additive, applicable to diesel enginesonly with 1:2000 proportions. This additive helps to inject high quality of fuelit occurs due to fine atomization laterenters into the combustion chamber that developed good combustion so, it produces best mechanical work and also protects from corrosion.

\section{PROPERTIES}

Table 1: Properties

\begin{tabular}{|c|l|c|}
\hline S.No & \multicolumn{1}{|c|}{ Property } & \multicolumn{2}{|c|}{ Additive } \\
\hline 1 & Density $(\mathrm{g} / \mathrm{ml})$ & $0.795 \quad$ at $29^{\circ} \mathrm{C}$ \\
\hline 2 & Vapour pressure & $0.796 \quad$ millibar \\
\hline 3 & Lower Explosion Limit & $0.9 \%$ \\
\hline 4 & Upper Explosion Limit & $7 \%$ \\
\hline 5 & Auto Ignition Temperature & $210^{\circ} \mathrm{C}$ \\
\hline 6 & Flash point & $>21^{\circ} \mathrm{C}$ and $<55^{\circ} \mathrm{C}$ \\
\hline
\end{tabular}




\section{ENGINE SPECIFICATIONS}

- Set up Single Cylinder Four Stroke (1C 4S) Diesel Engine

- $\quad$ Mode HMT04

- Make Comet oil Engine Ltd.

- Ignition system Compression Ignition

- Arrangement of Cylinder Vertical

- Cooling Water cooled

- $\quad$ Bore $0.080 \mathrm{~m}$

- $\quad$ Stroke $0.11 \mathrm{~m}$

- Compression ratio

- $\quad$ Speed $1500 \mathrm{RPM}$

- $\quad$ Rated Power $5 \mathrm{HP}$ at $2000 \mathrm{RPM}$.

\section{STANDARD PROCEDURE}

- Maintain the injection pressure at 200bar.

- Follow the Precautions, before starting the experiment.

- $\quad$ To avoid damage to pressure sensor, temperature should not exceed $121^{\circ} \mathrm{C}$.

- The engine was started with null load and wait for steady state at least 10 minutes to stabilize.

\section{EXPERIMENTAL PROCEDURE}

- Switch ON the ignition to do the experiment after installation set up was done on the engine.

- Mention the readings such as Load in $\mathrm{kg}$, time in seconds for calculate the fuel consumption at 20cc\& speed in rpm.

- $\quad$ Repetitivethe procedure as mention as above up to full load.

- With the help of engine controls, load was increased up to full load.

- After done this procedure, the entire loads were released later switch OFF the ignition.

- Getting outcome with standard formulas.

\section{METHODOLOGY}

The test is carried by the following manner:

Initially, experiment was performed by using pure diesel and further four types of blends B10, B20, B30 \& B40 in sequence. During B10 procedure, the proportion of diesel will be $90 \%$ and $10 \%$ of esterified waste cooking oil. Both are 
mixed well with the help of stirrer as per proportion for respective blends. Similarly the percentage of proportion carried out for other blends are listed below.

- $\quad$ B20: 20 Percent of esterifiedwaste cooking oiland 80 percentof Diesel

- $\quad$ B30: 30 percent of esterifiedwaste cooking oiland 70 percent of Diesel

- B40: 40 percent of esterified waste cooking oil and 60 percent of Diesel

After completing the experiment as mentioned above, calculate the performance were we get better outcome for that particular blend we add SC5D additive.

$20 \%$ waste cooking oil $+80 \%$ Diesel $+0.5 \mathrm{ml}$ additive

\section{RESULTS}

The Brake Specific Fuel Consumption (BSFC) is depends on the parameters i.e. Total Fuel Consumption and Brake Power. The BSFC is occurred at lower value; as a result good combustion takes place in the combustion chamber.The Load versus Brake Specific Fuel Consumption for various blends and B20 blend with additive when compared to diesel are shown in following figure 1 and figure 2 .

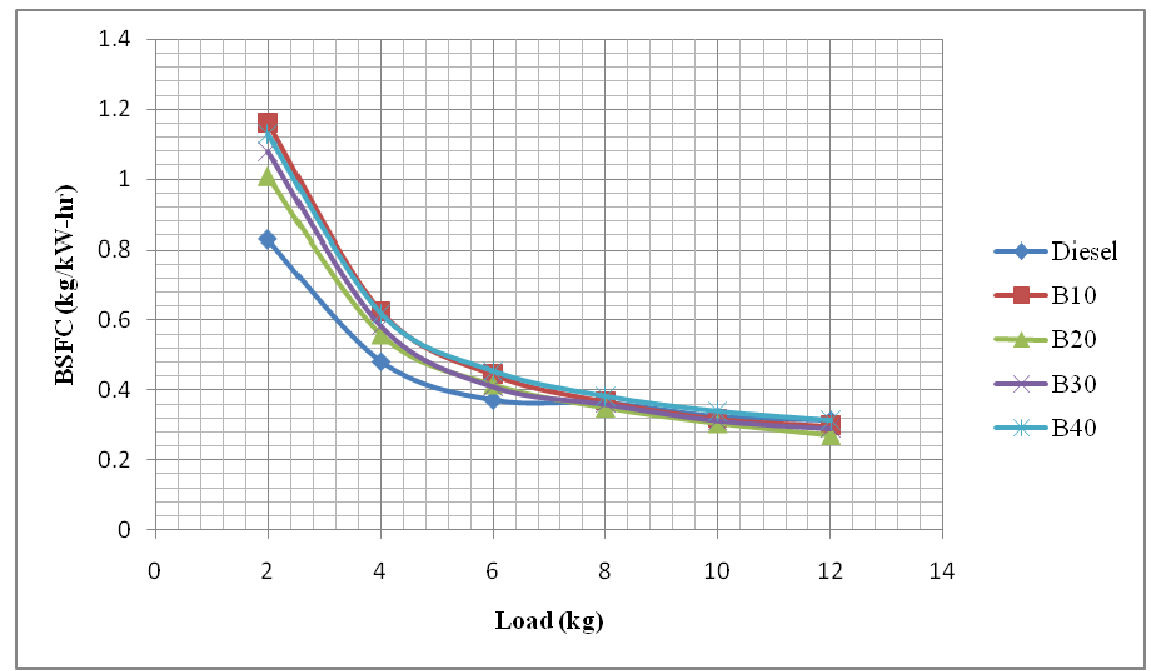

Figure 1: Load Vs Brake Specific Fuel Consumption. 


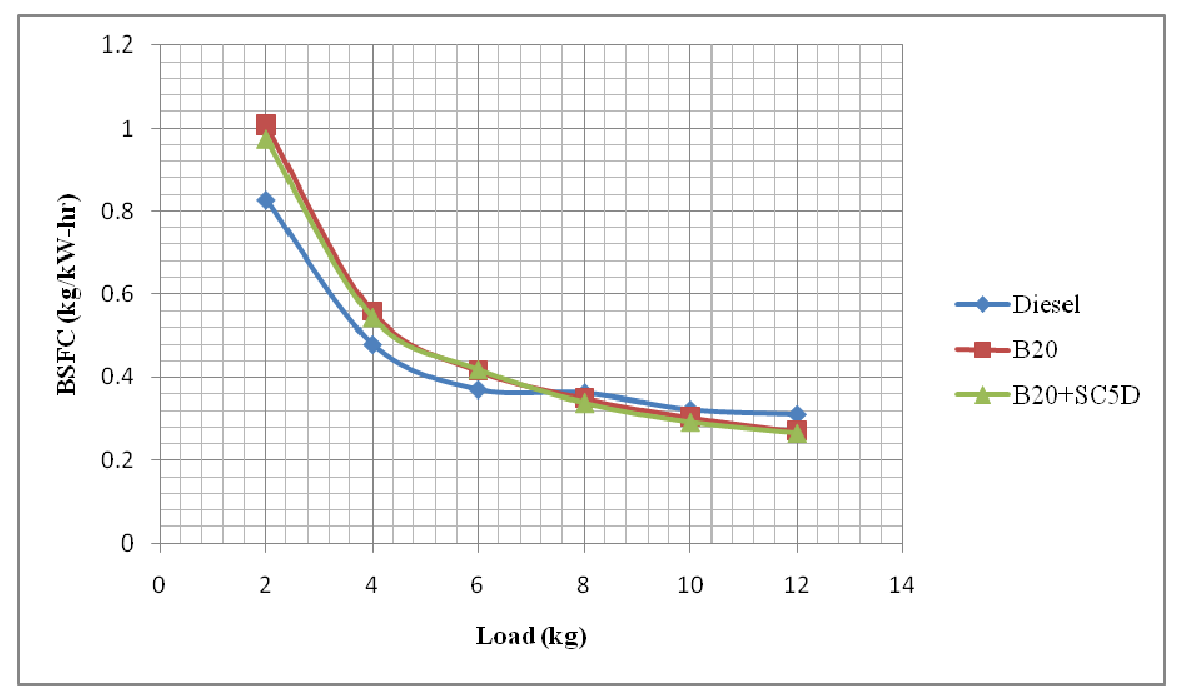

Figure 2: Load Vs Brake Specific Fuel Consumption.

The Brake Thermal Efficiency $\left(\eta_{\mathrm{bth}}\right)$ is depends on the parameters i.e. Brake Power and Heat Input. The $\eta_{\mathrm{bth}}$ is occurred at higher value, and it depends on the fuel consumption. The fuel consumption is less the $\eta_{\text {bth }}$ is increased. The Load versus Brake Thermal Efficiency for various blends and B20 blend with additive when compared to diesel are shown in following figure 3 and figure 4.

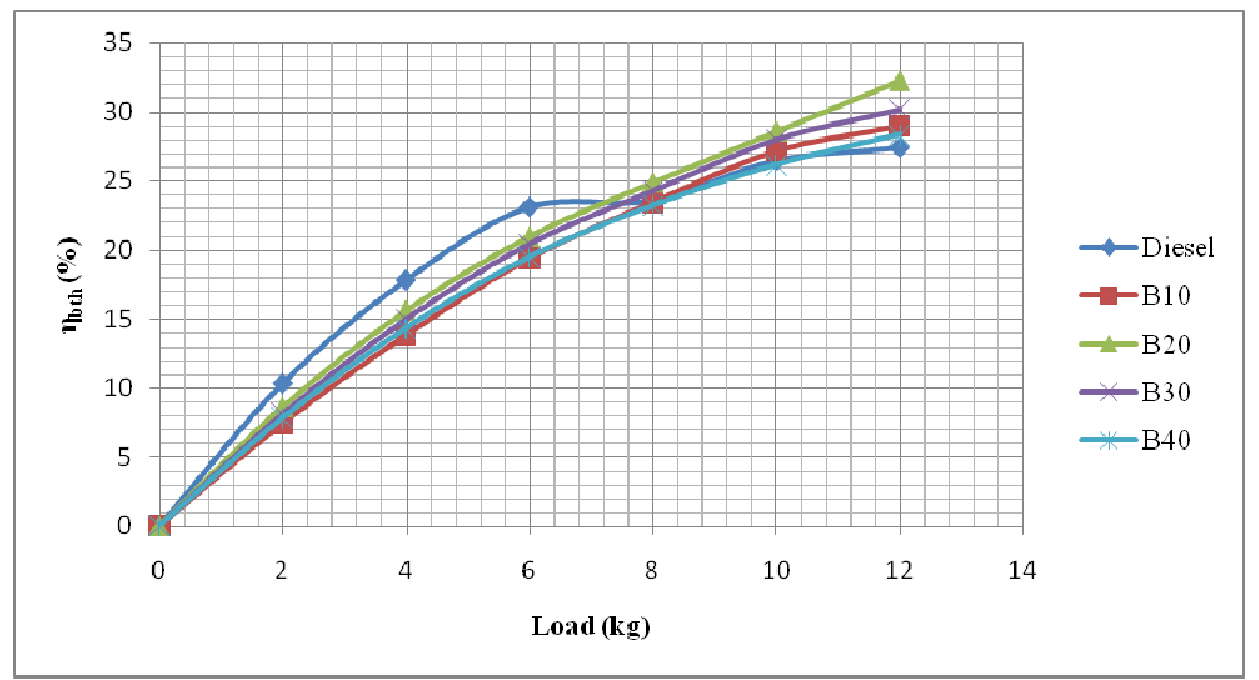

Figure 3: Load Vs Brake Thermal Efficiency. 


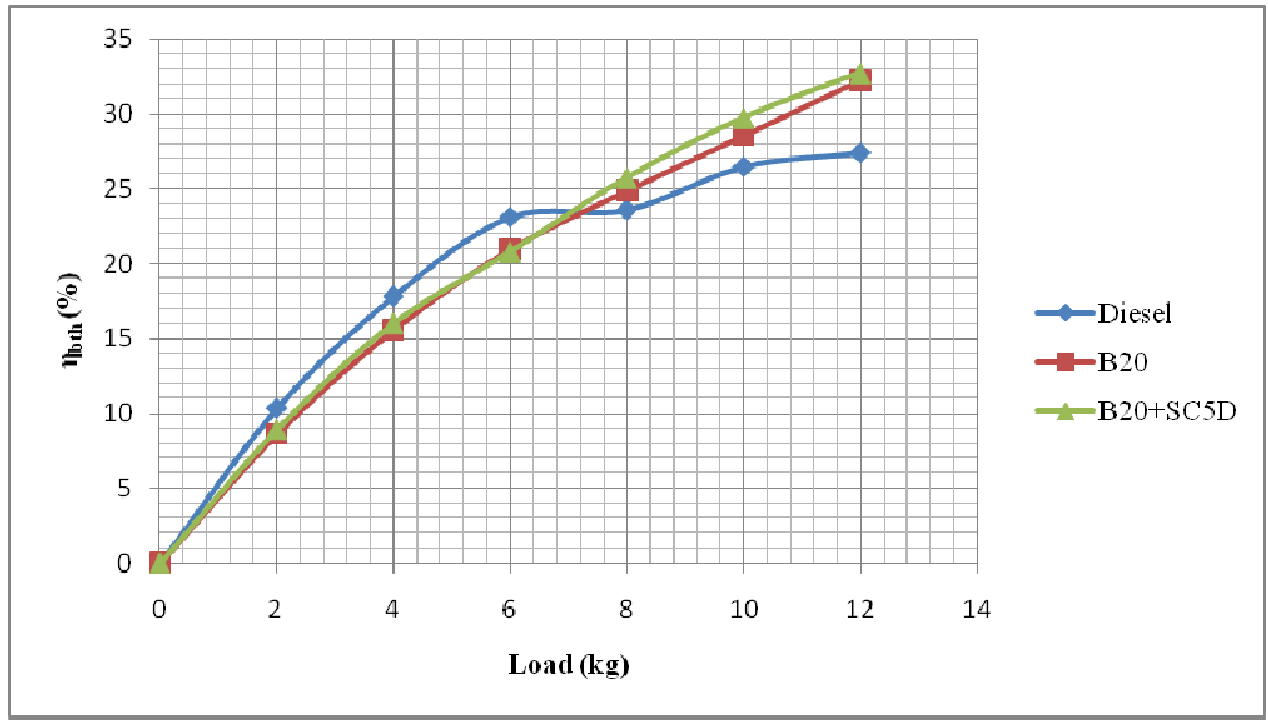

Figure 4: Load Vs Brake Thermal Efficiency.

The Indicated Thermal Efficiency $\left(\eta_{\text {ith }}\right)$ is depends on the parameters i.e. Indicated Power and Heat Input. The $\eta_{\text {ith }}$ is occurred at higher value, and it depends on the fuel consumption. The fuel consumption is less the $\eta_{\text {ith }}$ is increased. The Load versus Indicated Thermal Efficiency for various blends and B20 blend with additive when compared to diesel are shown in following figure 5 and figure 6.

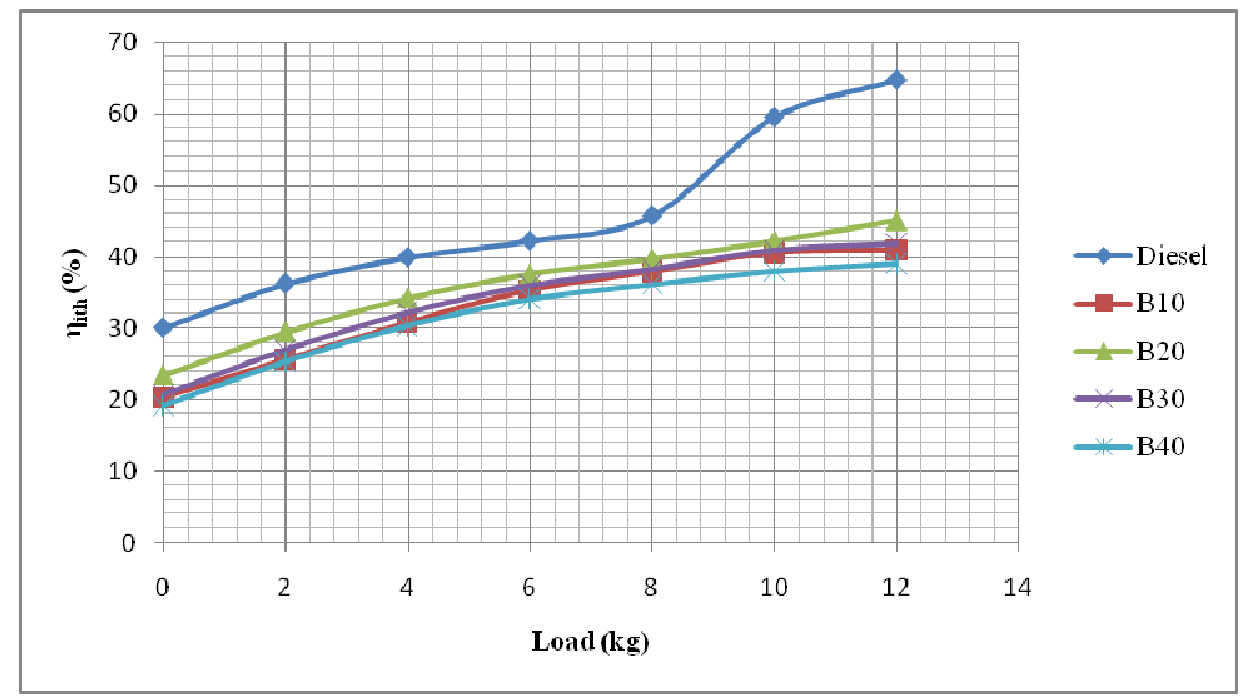

Figure 5: Load Vs Indicated Thermal Efficiency. 


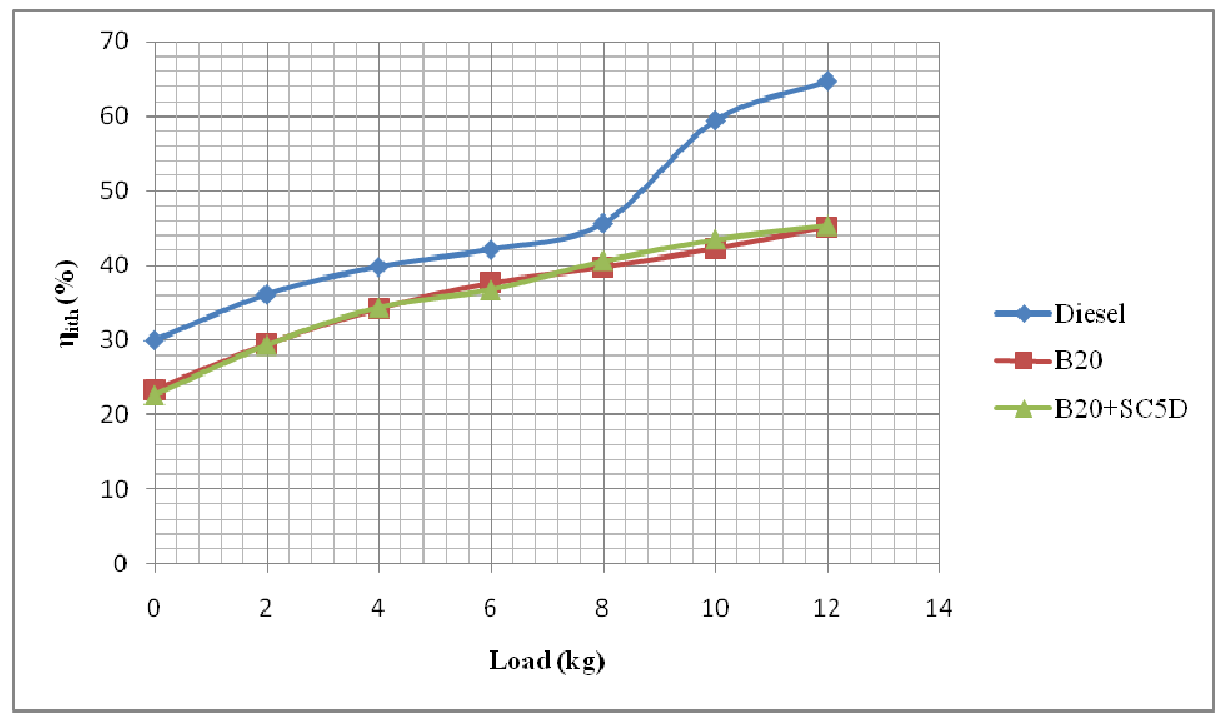

Figure 6: Load Vs Indicated Thermal Efficiency.

The Mechanical Efficiency $\left(\eta_{\text {mech }}\right)$ is depends on the parameters i.e. Brake Power and Indicated Power. The Load versus Mechanical Efficiency for various blends and B20 blend with additive when compared to diesel are shown in following figure 7 and figure 8 .

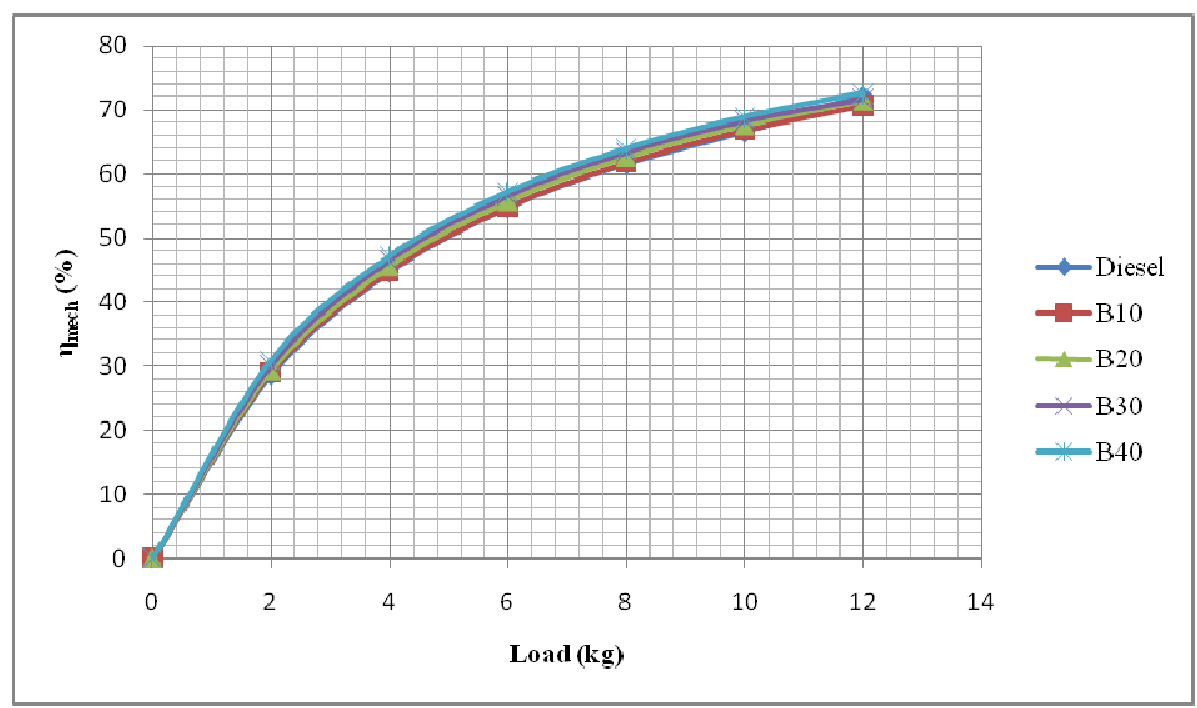

Figure 7: Load Vs Mechanical Efficiency. 


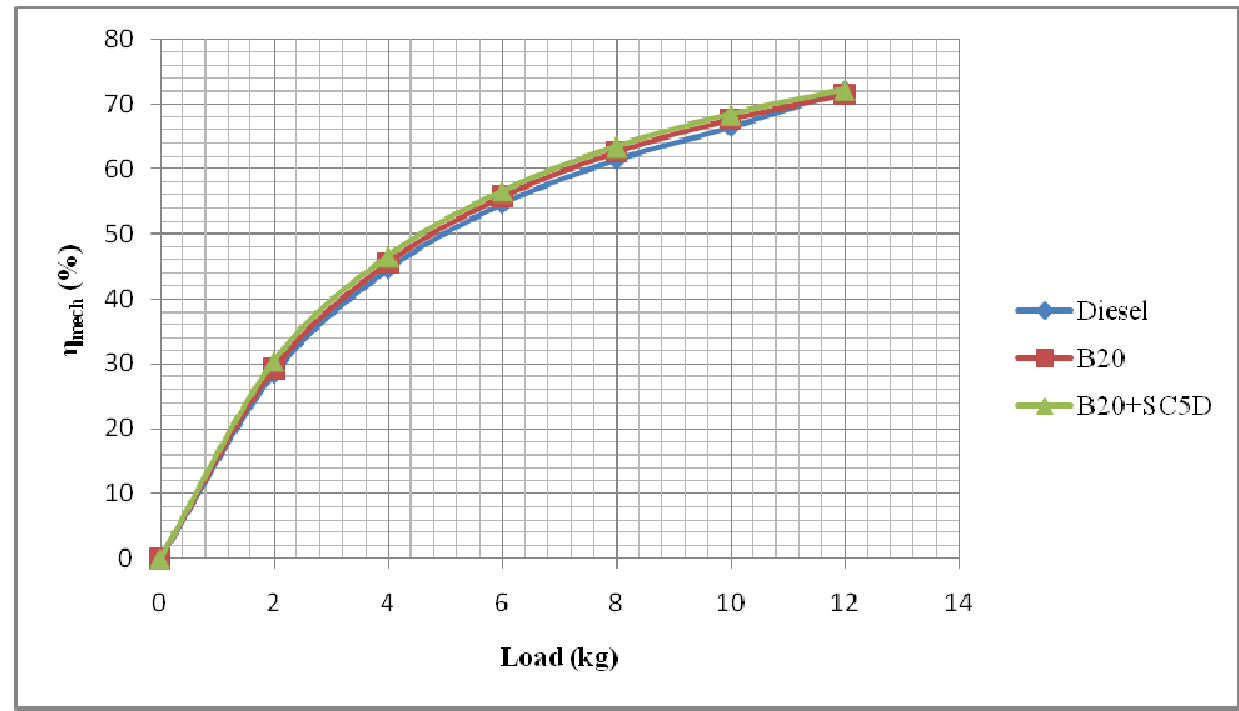

Figure 8: Load Vs Mechanical Efficiency.

The Brake Mean Effective Pressure (BMEP) is depends on the parameters i.e. Brake Power and engine specifications (Stroke, Area of the Bore, Speed and Number of cylinders). The BMEP is occurred at higher value, and the BMEP is the average effective pressure throughout the whole power stroke. In fact the cylinder pressure varies considerably during the power stroke.The Load versus Brake Mean Effective Pressure for various blends and B20 blend with additive when compared to diesel are shown in following figure 9 and figure 10.

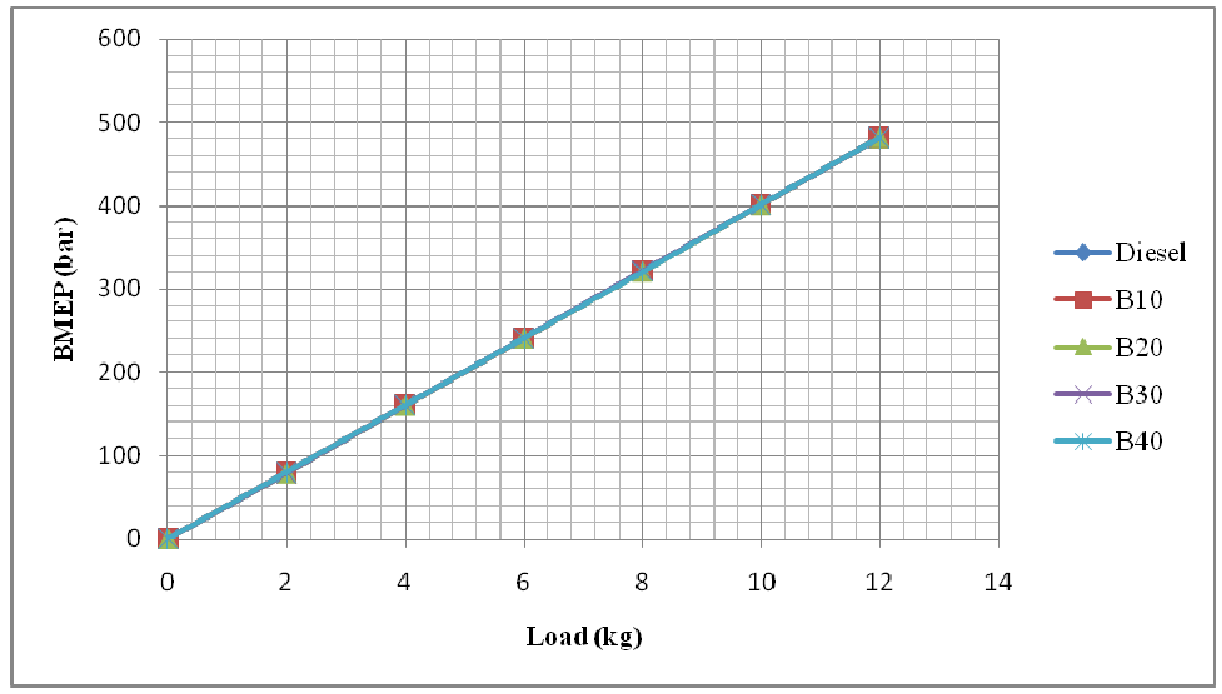

Figure 9: Load Vs Brake Mean Effective Pressure. 


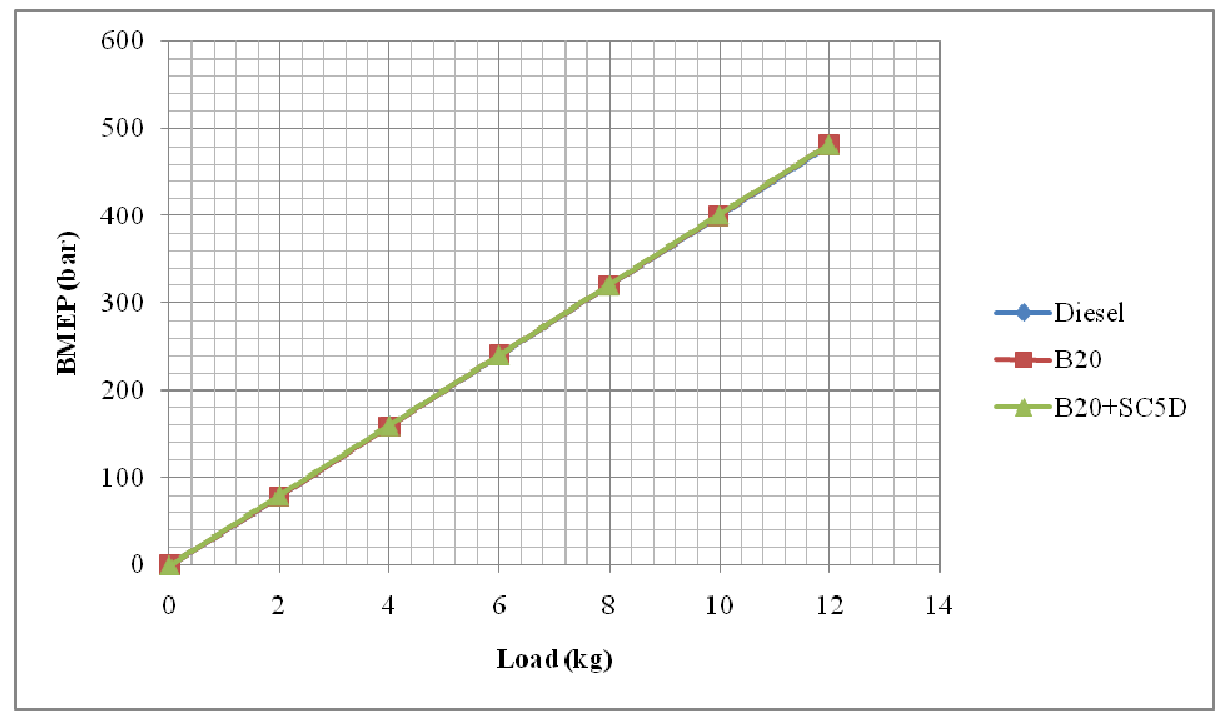

Figure 10: Load Vs Brake Mean Effective Pressure.

The Indicated Mean Effective Pressure (IMEP) is depends on the parameters i.e. Indicated Power and engine specifications (Stroke, Area of the Bore, Speed and Number of cylinders). The IMEP is occurred at higher value, and the IMEP is the average effective pressure throughout the whole power stroke. In fact the cylinder pressure varies considerably during the power stroke.The Load versus Indicated Mean Effective Pressure for various blends and B20 blend with additive when compared to diesel are shown in following figure 11 and figure 12.

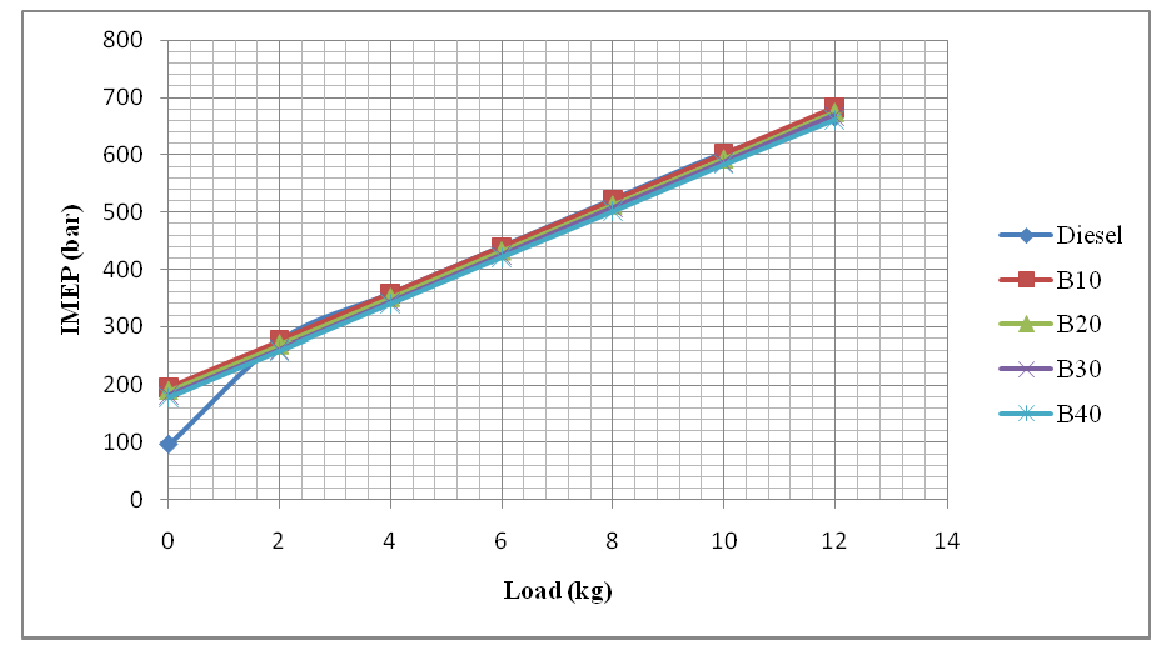

Figure 11: Load Vs Indicated Mean Effective Pressure. 


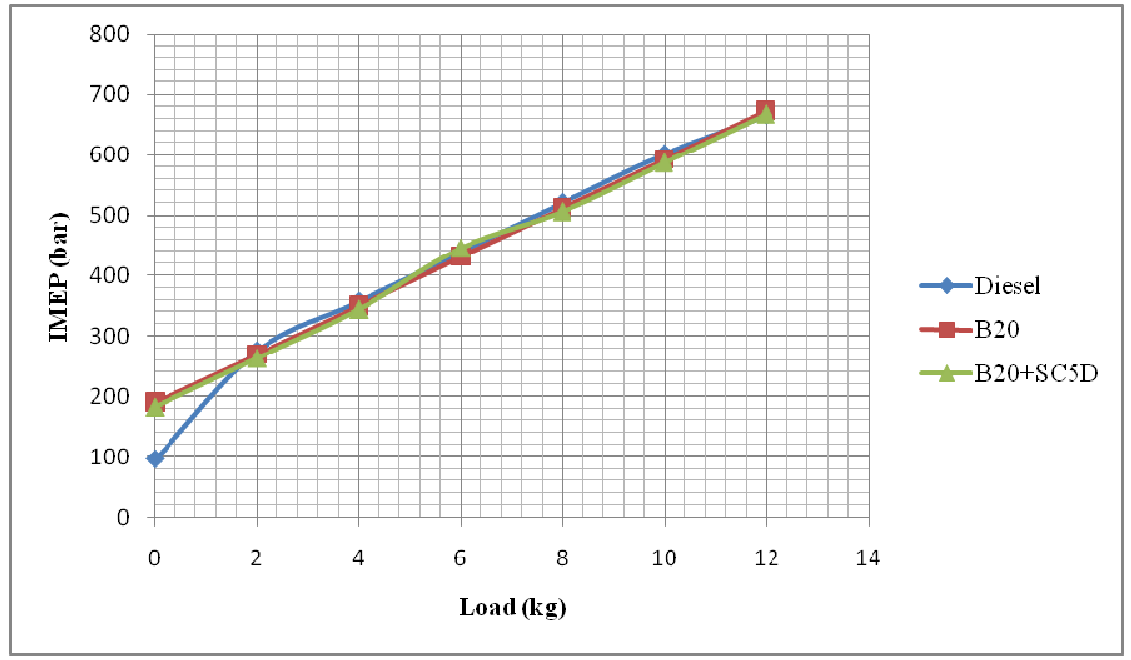

Figure 12: Load Vs Indicated Mean Effective Pressure.

\section{CONCLUSIONS}

- By adding $0.5 \mathrm{ml}$ of SC-5D additive to B20, it minimizes the Specific Fuel Consumption(SFC) around 0.5\% compared to pure diesel.

- By adding $0.5 \mathrm{ml}$ of SC-5D additive to B20, itmaximizes the Brake Thermal Efficiency $\left(\eta_{\mathrm{bth}}\right)$ nearly $1.2 \%$ compared to pure diesel.

- By adding $0.5 \mathrm{ml}$ of SC-5D additive to B20, it minimizes the Indicated Thermal Efficiency $\left(\eta_{\text {ith }}\right)$ more than $10 \%$ compared to pure diesel. But we observed fluctuations in it.

- By adding $0.5 \mathrm{ml}$ of SC-5D additive to B20, it maximizes the Mechanical Efficiency $\left(\eta_{\text {mech }}\right)$ almost $2 \%$ compared to pure diesel.

- By adding $0.5 \mathrm{ml}$ of SC-5D additive to B20, itmaximizes the Brake Mean Effective Pressure(BMEP) in the region of $1 \%$ compared to pure diesel.

- By adding $0.5 \mathrm{ml}$ of SC-5D additive to B20, itmaximizes the Indicated Mean Effective Pressure(IMEP) about $10 \%$ compared to pure diesel.

- As a result, bymeans of 20 percent of waste cooking oil +80 percent of Diesel $+0.5 \mathrm{ml}$ additive fuelled engine was increased the performance parameters those are listed above when compared to diesel fuelled engine.

- Concluded was the B20 with $0.5 \mathrm{ml} \mathrm{SC-5D}$ additive could be suggested as an alternate fuel to dieselfor getting the better performance.

\section{REFERENCES}

1. ZahiraYaakob et al, (2013) Overview of the production of biodiesel from waste cooking oil", Renewable and Sustainable Energy Reviews.

2. Renato Cataluna,(2011) "Acceleration test using gasoline's formulated with di-TAE,TAEE and MTBE ethers, Fuel", vol-90, Elsevier.

3. Naik, R. T., and C. Nilesh. "Emission characteristic of a high speed diesel engine." International Journal of Mechanical 
Engineering, 5, 2936 (2016).

4. Rong-Horng, (2011) "Cold-start emission of an engine using ethanol-gasoline blended fuel", Applied Thermal Engineering, vol-31, Elsevier.

5. Oghenejoboh Ket al, (2007) 'Effects of Air Pollution Arising from Associated Gas Flaring on the Economic Life of the People of Oil Producing Communities in Nigeria' Vol. 23, No. 1, pp. 1-9, Journal of Industrial Pollution Control.

6. J.M. Marchettiet al, (2005) "Possible methods for biodiesel production".

7. Krishna, MVS Murali, and K. Vamsi Krishna. "Studies on Exhaust Emissions of Di Diesel Engine with Low Grade LHR Combustion Chamber Fuelled with Linseed Biodiesel." International Journal of Mechanical Engineering (IJME) 3.6 (2013): 63-72.

8. T. Nibin et al, (2005) "Investigation on emission characteristics of a diesel engine using oxygenated fuel additive” Vol.86, pp: 51-54, Institute of Engineers (India).

9. Bajpai, D. and Tyagi, V. K. (2005) “Biodiesel: Source, Production, Composition, Properties and its Benefits”, 55 (10): 487 488, J. Oleo Sci.

10. W. Yanxia et al, (2004) "Diesel Engine Emission Improvements by the Use of EGM-DMC-Diesel BlendsFuel”, pp: 90-94, 5th WSEAS Int. Conf. on EE\&D.

11. Srikanth, D., et al. "Performance exhaust emissions, and combustion characteristics of cotton seed oil based biodiesel in ceramic coated diesel engine." International Journal of Mechanical Engineering 2.5 (2013): 67-82.

12. FarhadNadim, (2001) "United States Experience with gasoline additives Energy Policy", vol-29, Elsevier.

13. Z Huang, (2001) "Combustion characteristics and hydrocarbon emissions of a spark ignition engine fuelled with gasolineoxygenate blends," vol-3, Journal of Automobile Engineering.

14. Ayoola, A. A., et al. "Comparison Of The Properties Of Palm Oil And Palm Kerneloil Biodiesel In Relation To The Degree Of Unsaturation Of Their Oil Feedstocks." International Journal of Applied And Natural Sciences 5.3 (2016): 1-8.

15. Smith, H. A. (1983) "Dialkyl Carbonates asPhase Separation Inhibitors in Liquid Hydrocarbon Fueland Ethanol Mixtures"; US Patent 4,380,455, assigned to Dow.

16. Text book of Internal Combustion Engines by V. Ganeshan.

17. Text book of Internal Combustion Engines by K.L. Mathur and Sharma.

18. Text book of heat engines by John Heywood.

19. Text book of Alternative fuels by S.S.Thipse. 